\title{
Simulation of sound transmission through the porous material, determining the parameters of acoustic absorption and sound reduction
}

\author{
Peter Zvolenský, ${ }^{1, *}$, Juraj Grenčík ${ }^{1}$, Lubomír Kašiar ${ }^{1}$, Vladimír Stuchlý ${ }^{1}$ \\ ${ }^{1}$ Department of Transport and Handling Machines, Faculty of Mechanical Engineering, University \\ of Zilina, Slovak Republic, Univerzitná 8215/1 01026 Zilina, Slovak Republic
}

\begin{abstract}
Currently, the quality of structural design of a railway coach is evaluated by so called acoustic comfort, which is characterized by achieved levels of internal noise. Therefore, acoustic parameters of car body are being developed purposely. The paper presents the results of the computer simulation of noise transmission through the wagon walls and the use of noise tests from the train running. The acoustic properties of the original and new materials in the care body are compared.
\end{abstract}

Keywords: simulation of noise transmission, noise of railway vehicles

\section{Introduction}

Currently in the EU, increased attention is paid to reducing rail noise, so all EU Member States are doing research in the area of noise reduction. In particular, technical solutions in the field of railway vehicle design, track structure and technological aspects of rail traffic can effectively reduce the noise emitted by the operation of a railway vehicle. Possible approaches in this area can be defined mainly in the following aspects:

- Investigation of noise sources and vibration sources and noise propagation pathways,

- Simulation and modelling of the noise fields generation and their impact on the surroundings and passengers,

- Verification of theory and computer modelling by experimental research in traffic conditions,

- Evaluation and development of noise reduction procedures and methods applied on the design of relevant railway vehicles.

The reduction of railway noise requires the research of the above-mentioned interconnected areas as components of the system. In railway traffic, we meet with two ways of noise reduction:

- Urgent acute noise abatement usually resulting from measured noise exposure situations detected mainly by state supervision, e.g. noise affecting residential areas, or passengers in the interior of a railway vehicle,

\footnotetext{
* Corresponding author: peter.zvolensky@fstroj.uniza.sk

Reviewers: Jerzy Jaroszewicz, Josef Soukup
} 
- The conceptual task required by legislation or environmental policy of the EU, or individual states, e.g. concept of formation and international transit of "silent trains".

Often the modern rolling stock designs in terms of assessment and noise emissions are mostly at the limit of existing possibilities. Also, the approaches of the secondary solution (acoustic barriers, car body design, aerodynamics of the shape of a railway vehicle body, the use of modern materials) are relatively well worked out. Different design and interior materials also have well-defined parameters of airborne sound and sound absorption. At the same time, the use of modern materials and technologies that effectively promote recycling is of particular importance today. The rapid transfer of scientific knowledge and the results of experimental research in the field of noise emissions from rolling stock into transport practice bring new opportunities, tools and approaches to the effective improvement of the quality of the environment $[1,2,3,4]$.

\section{Application of porous acoustic materials in simulation of acoustic energy transfer through the structure of a rail passenger wagon floor}

Research that is associated with the acoustic properties of porous materials needs to be applied in practice. From the point of view of the objective assessment of the noise emissions generated by the rolling stock, it is necessary to identify the origin and sources of noise on a railway passenger car and also the type and pathways of spreading acoustic energy into the structure and the surrounding area. This space represents not only the transport communication and its immediate surroundings, but also the interior of a vehicle, where the passengers are exposed to the noise. In the general interest, it is necessary to address the possibilities, the ways and the new technologies for reducing the noise in the interior of the means of transport, not only in the automotive industry, which is the major leader in the research of new technologies for the production and application of acoustic materials, but also on the railway. It is an integral part of the business strategy of manufacturers and operators of the means of transport in general. By this the comfort of transport is being improved and it directly affects the final customer, that is, the passenger when choosing a suitable means of transport.

At present, numerous modern technical and technological solutions for noise reduction are being used in the development of new vehicle designs. One of the frequent trends is the research and development of new acoustic materials and the way they are used.

There is a wide range of modern thermal and sound-insulating materials on the market. These materials are used in the design of new rolling stock. In recent years, ZSSK (Railway Company Slovakia) has been modernizing its fleet and thus offering a good opportunity to improve the acoustic properties not only of the floor but also of the entire car body in the modernization of passenger railway wagon. Therefore we have also focused our research on the design the Bdghmeer railway wagon. In the design of the floor of the Bdghmeer passenger railway wagon, mineral wool is currently used as a heat-insulating and soundinsulating material. During the modernization only the old insulation layer is replaced by the new one. The research at the Department of transport and handling machines was also focused on the design of new acoustic and thermal insulation materials in the wagon floor structure.

The simulation processes of sound propagation in liquids and solids in simulation tools are based on several mathematical models. From the point of view of the requirements of the airborne sound reduction of the floor structure of a passenger railway wagon, mineral wool and newly designed STERED ${ }^{\circledR}$ material has important role. In both cases, these are porous materials with a fibrous microstructure. The acoustic energy is predominantly 
converted to thermal energy, while the sound propagation in the porous structures is determined by the ability of the air to propagate through the pores of the microstructure and also by vibrations that propagate through the solid structure of the fibrous material, in this case the fibres. The sound waves propagate through the fibres. An example of the flow of fluid (air) through the porous structure is shown in Figure 1.

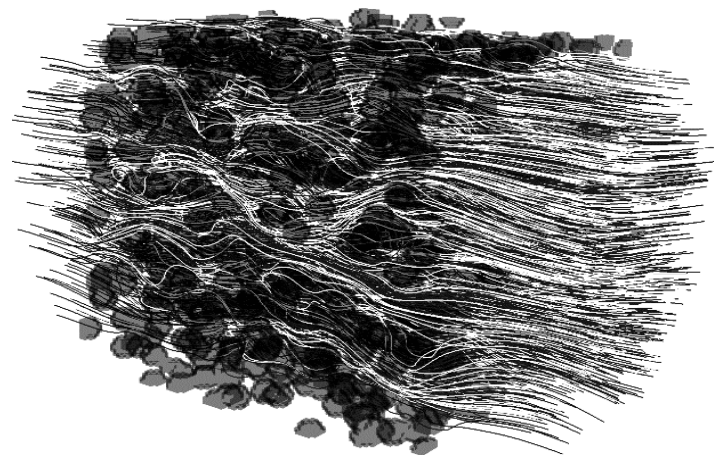

Fig. 1. Transfer of fluid through the structure of the porous medium [5]

A scientific discipline that deals with propagation of sound in porous substances is called "porous acoustics or acoustics of porous materials". By defining appropriate parameters for a porous material, the simulation program is able to create a model of the porous structure of the material and use it to simulate the transmission of acoustic energy through this structure. From the research of the acoustic properties of porous materials it implies that the most significant effect on acoustic parameters such as sound absorption and airborne sound reduction has the so-called viscous characteristic length $L v$. It is a parameter that determines the mean value of the macroscopic dimensions of the channels that bind the individual pores of the material structure. Simulations within the investigation of the acoustic parameters of the wall of the monitored passenger wagon were mainly focused on determining the sound reduction and sound absorption of the original solution using the mineral wool and verifying these acoustic properties using the new progressive material STERED $^{\circledR}$.

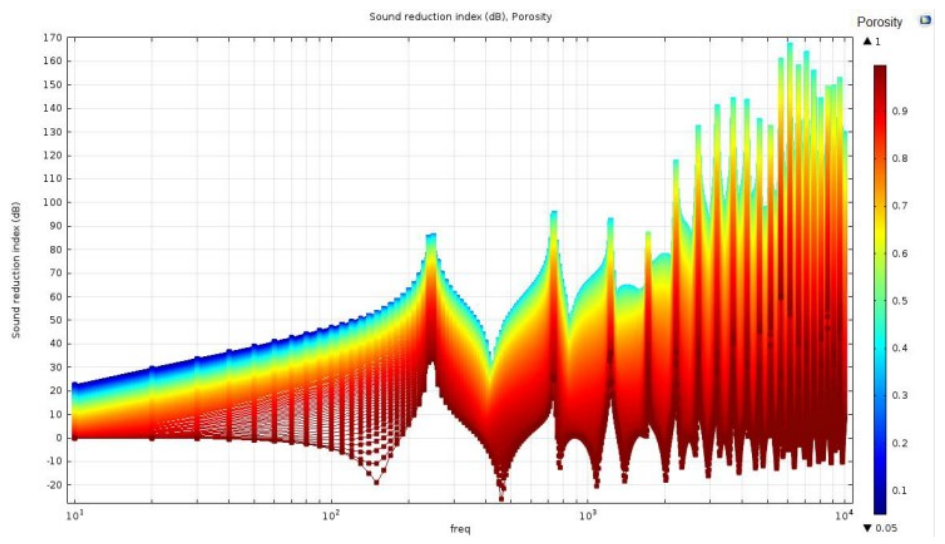

Fig. 2. Frequency dependence of airborne sound reduction index on the porosity of fibrous material

From the simulations obtained, original 3D charts have been created that declare the properties, which are damping capabilities of the investigated structure and materials used. In the figure 2 is an example of simulation for determining the sound reduction of the porous material. 


\section{Simulation of acoustic energy transfer through porous media}

The role of simulation tools is to approximate as much as possible the actual physical actions which are constantly ongoing in nature. Simulation software works on the basis of mathematical models (Fig. 3), which were mostly derived from empirical relationships obtained on the base of sufficient number of relevant experiments.

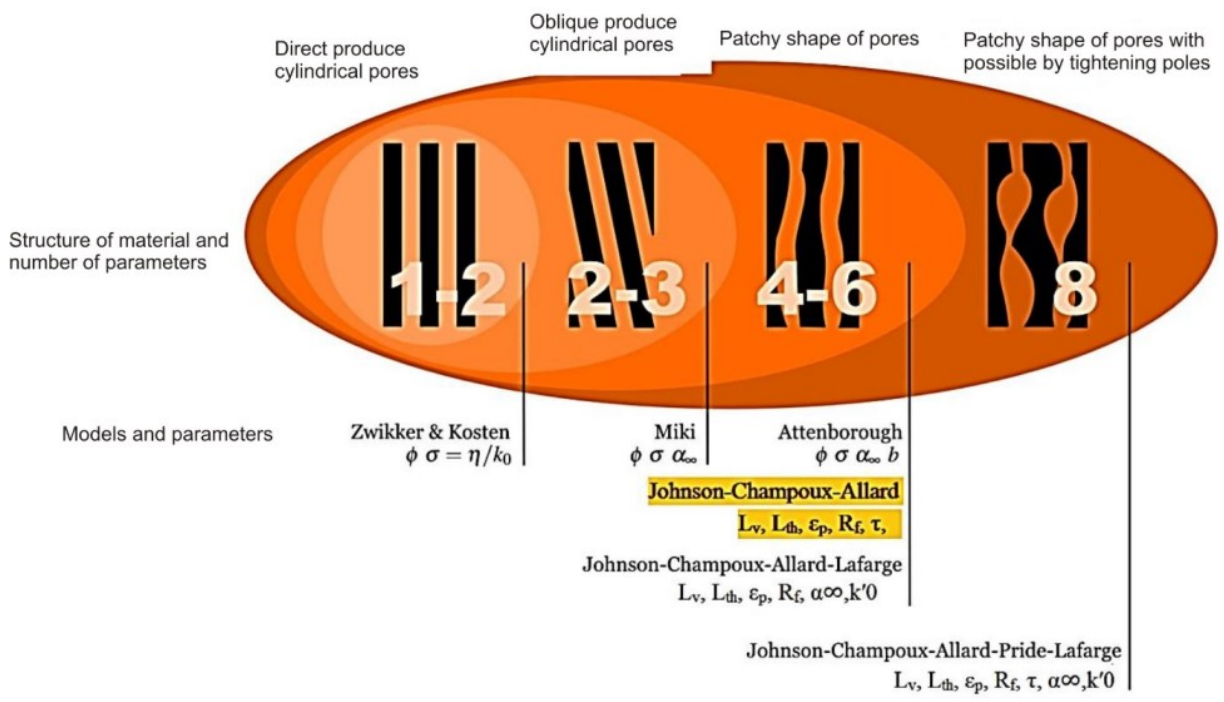

Fig. 3. The most used mathematical models and parameters necessary for the formation of a porous structure [5]

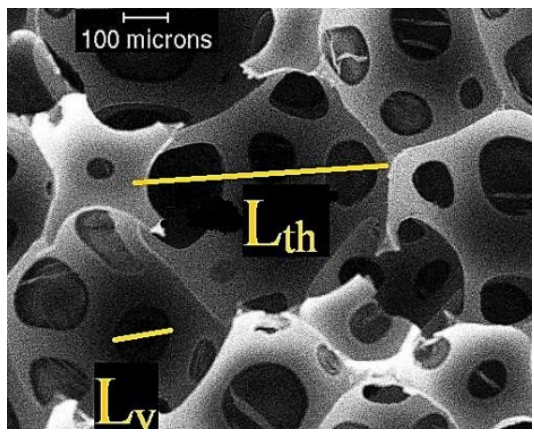

Fig. 4. Thermal and viscous characteristic pores length - from the microscopic image of polyurethane foam [6]

The simulations use different mathematical models on which the calculation and simulation of acoustic energy transfer through the porous structure runs (Fig. 4) [7].

Thermal and viscous characteristic length directly determines the texture, shape and arrangement of pores, or fibre porous structure. The equation for their calculation is as follows:

$$
\mathrm{L}_{\mathrm{v}}=\sqrt{\frac{8 \mu \tau}{\varepsilon_{\mathrm{p}} \mathrm{R}_{\mathrm{f}}}} \quad[\mathrm{m}]
$$


where:

$L v$ - viscous characteristic length,

$\mu$ - dynamic viscosity of air, which is in the pores,

$\varepsilon p$ - porosity,

$R f$ - airflow resistance.,

$\tau$ - curvature pores impact factor (Fig. 5).

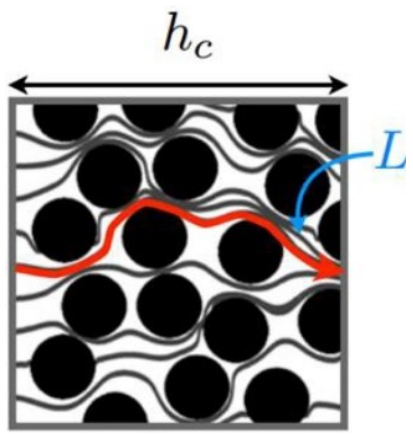

Fig. 5. Curvature pores impact factor [8]

Curvature pores impact factor can be calculated as:

$$
\tau=\frac{\mathrm{L}}{\mathrm{h}_{\mathrm{c}}} \quad[-]
$$

where:

$L$ - sound pressure level, $h c$ - board thickness.

The empirical formula for calculating of the air flow resistance is as follows:

$$
\mathrm{R}_{\mathrm{f}}=\frac{3,2 \mu\left(1-\varepsilon_{\mathrm{p}}\right)^{1,42}}{\mathrm{a}^{2}} \quad\left[\mathrm{~Pa} \cdot \mathrm{s} \cdot \mathrm{m}^{-2}\right]
$$

where:

$a$ - the mean fibre diameter.

Curvature pores impact factor of the fibre structure can be calculated according to the empirical formula:

$$
\tau=\frac{1}{\varepsilon_{\mathrm{p}}^{\frac{1}{2}}}
$$

or it can be estimated from the detailed study of the microstructure microscopic image in the following manner. By substituting these equations into the equation 1 we obtain equation in this form:

$$
\mathrm{L}_{\mathrm{v}}=\sqrt{\frac{8 \mu \varepsilon_{\mathrm{p}}^{\left(-\frac{1}{4}\right)}}{\varepsilon_{\mathrm{p}} \frac{3,2 \mu\left(1-\varepsilon_{\mathrm{p}}\right)^{1,42}}{\mathrm{a}^{2}}}} \quad[\mathrm{~m}]
$$


Research on acoustic properties of porous materials showed that the most significant effect on the acoustic parameters, such as sound absorption and airborne sound insulation has a viscous characteristic length $L v$. It is a parameter which determines the mean value of dimensions macro-channels, which connect the individual pores of the material structure. Here rise the viscous losses of sound energy, when air pressure changes permeating from one pore to another through a channel that connects these pores. Parameter called thermal characteristic length Lth is derived from the viscous characteristic length. It indicates the mean macroscopic pore size of the porosity structure [9].

Mineral wool and STERED ${ }^{\circledR}$ are porous fibrous materials. Decisive influence on the acoustic properties of porous materials has just the porosity. The porosity influence of the fibrous material on the acoustic properties has been studied by using of the simulated computation by the change of the porosity in a range from 5 to $99.5 \%$ by $0.5 \%$ and the frequency from $10 \mathrm{~Hz}$ to $10 \mathrm{kHz}$ by $10 \mathrm{~Hz}$.

Model presents a principle of the impedance tube (Fig. 6) and the inlet signal is defined by function in complex form. [9-11]

$$
1 \exp ^{(-\mathrm{i}(\mathrm{kx} \cdot \mathrm{x}+\mathrm{ky} \cdot \mathrm{y}))} \quad[\mathrm{Pa}]
$$

where:

$x$ - position vector of given environment oscillator in direction of application of $\mathrm{x}$-axis, $y$ - position vector of given environment oscillator in direction of application of y-axis, $k x$ - wave vector in the $\mathrm{x}$-direction of sound waves propagation, $k y$ - wave vector in the y-direction of sound waves propagation.

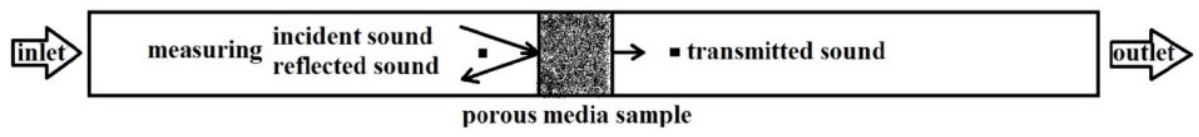

Fig. 6. Model of simulation of acoustics energy transfer through the porous media

The influence of material porosity on the sound reduction index and sound absorption coefficient is better observable on the graph, which was created by the separation of the specific frequencies (Fig. 7). The monitored characteristics of acoustic parameters at the frequency of $1 \mathrm{kHz}$ are given as an example (Fig. 8). 


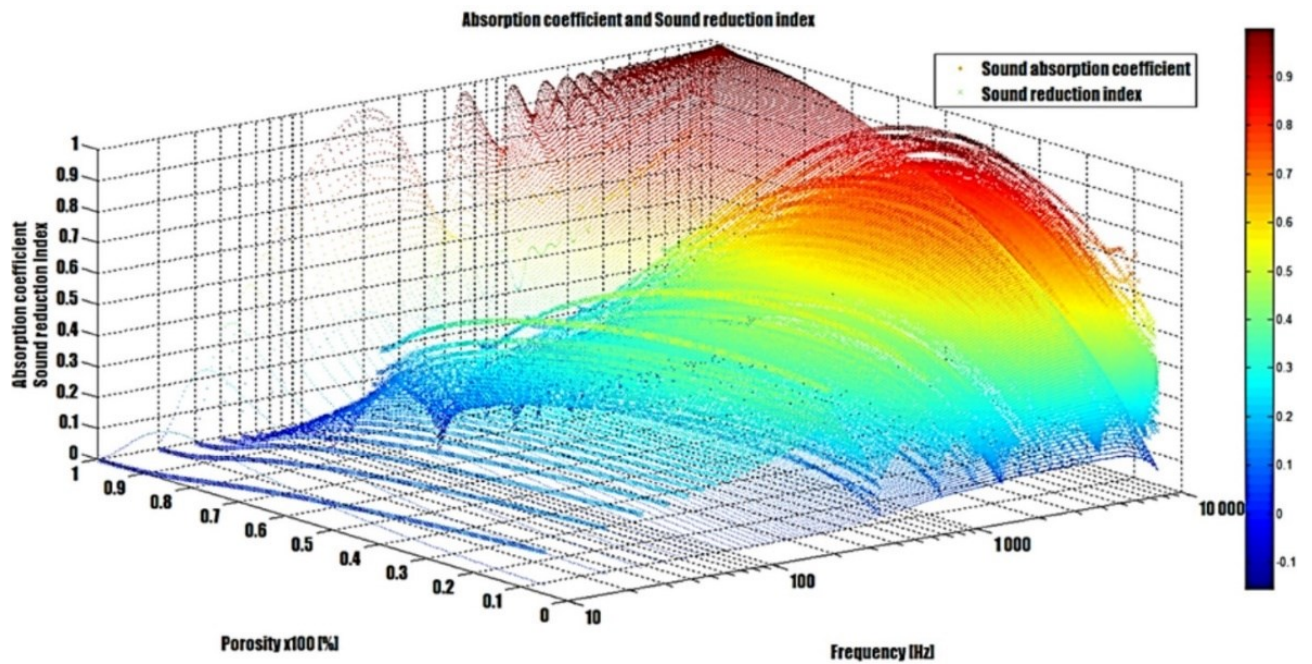

Fig. 7. Frequency dependence of sound absorption coefficient and sound reduction index on the material porosity

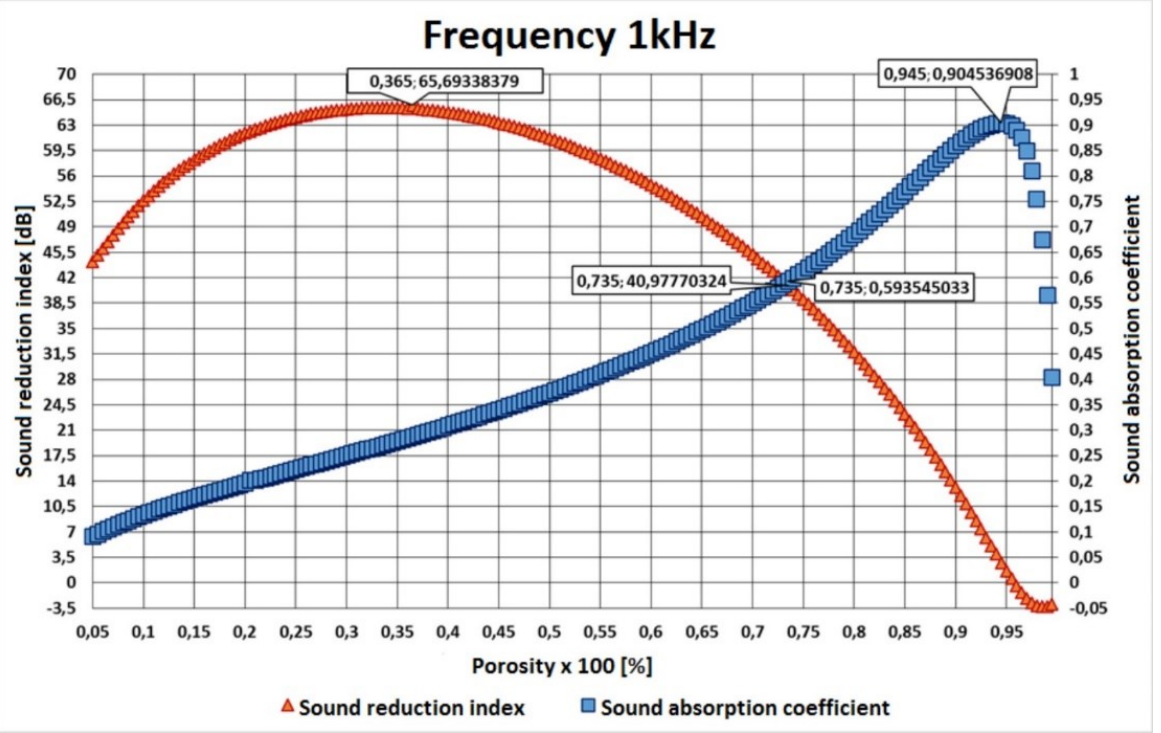

Fig. 8. The characteristic of sound reduction index and sound absorption coefficient depending on the material porosity in frequency $1 \mathrm{kHz}$

Model for investigation of the acoustic energy transfer through the porous material was created within the simulation. Related percent porosity of the material, its sound absorption and airborne sound insulation depending on the frequency of transferring acoustic energy was monitored. As an output example is presented the dependence at the frequency of $1 \mathrm{kHz}$, which is the best audible by human ear and so the simulation results of effects of noise on human body can be taken relatively objective.

The studied relationship is based on energy balance transfer of acoustic energy through the porous microstructure of fibrous material (Fig. 9). 


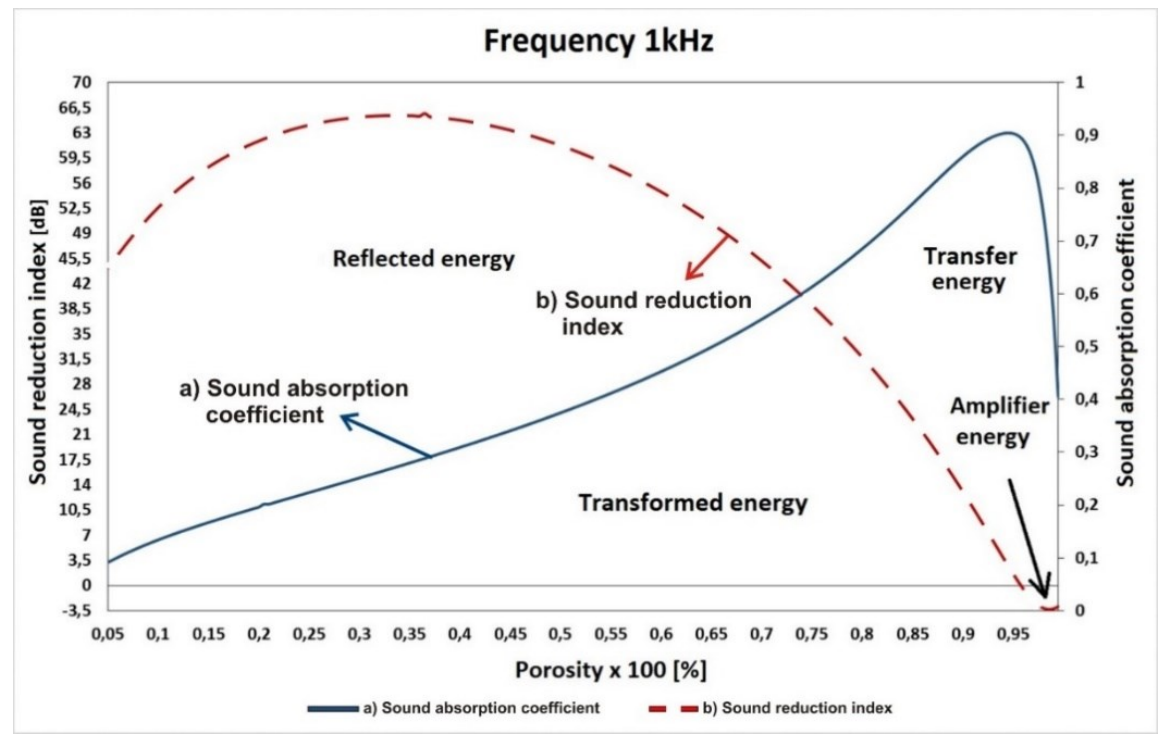

Fig. 9. Energy balance of the acoustic energy transfer through porous fibrous microstructure

The mathematical model can create a geometrical model of the fibrous material microstructure, which in principle works as a breaker of acoustic waves. The influence of the material porosity is important and therefore porosity measurement of mineral wool, material STERED ${ }^{\circledR} 200$ and STERED ${ }^{\circ} 250$ (Fig. 8) was performed, by using direct porosity measurement method. This method is suitable only for very regular-shaped test samples. The measured samples had to be saturated in the water under vacuum. The volume of pores was determined on the base of the water bulk density, which was in the pores of porous materials $[12,13]$.

\section{Measurement of internal and external noise of a passenger railway wagon}

Due to the need to perform simulation calculations of acoustic energy transmission through the structure of the floor of a passenger railway wagon and verifying the suitability of using the proposed STERED ${ }^{\circledR}$ acoustic material in this design, it was necessary to measure the internal noise and external noise that is acting in the space of running gear during train run and use the data obtained as an input for simulation calculations. Measurements were carried out on the modernized railway passenger wagon series Bdghmeer no. $615628-70$ 013-5 during the run on the selected section Prievidza-Leopoldov and LeopoldovBratislava track corridor. The passenger rail wagon was placed at the end of the train and locked for experimental purposes. The Bdghmeer four-axle wagon is designed for the transport of passengers and luggage and is also adapted for the transport of immobile passengers. Measurement was performed using the Pulse $3560 \mathrm{~B}$ measurement system from Brüel \& Kjær. Three measuring microphones Brüel \& Kjær, type 4188, were used for the measurements. Signal data for frequency analyses and sound pressure levels from three microphones were recorded during the measurement. The time of one measurement was 60 seconds for both measured quantities.

Measuring microphone no. 1 was placed in the exterior just above the ground and fixed to the floor frame structure to detect noise emission levels and frequency noise analysis of the source, the GP 200 bogie, during running at different speeds on the selected track section. Measuring microphone no. 2 was located in the disabled section in the rear of the 
wagon in the direction of travel, directly above the bogie. Data recorded by measuring microphone no. 1 and no. 2 could be compared immediately to determine the acoustic properties of the floor of the passenger wagon and the entire car body structure and at the same time they served as input data for simulation of the transmission of acoustic energy through the car body structure. The experimental results were confronted with the results of the simulations. Measuring microphone no. 3 was located in the aisle at a height of $1.2 \mathrm{~m}$ above the floor, near the door and the lifting platform for access of disabled passengers. The measured data were informative in order to assess the noise levels at different locations of the structure of the investigated wagon.

The measurement was not intended only to obtain sufficient data for simulation calculations but also for eventual studies and identification of the dynamic track effects and running speed on the noise emitted by the rolling stock. In each of the track sections, ten measurements were carried out and, due to an objective assessment of the impact of the speed and track dynamics of the track sections on the noise in the interior of the passenger railway wagon, the data were further processed and the determined the so called mean values of the sound pressure levels recorded in relation to time and frequency during running on different selected track sections, which differed by the track structure and the train speed. By comparing the resulting frequency and sound pressure levels measured by the M2 and M3 measuring microphones on the track sections concerned, we experience the significant effect of the track condition on the interior noise in the passenger rail wagon. In the case of the resulting frequency analyses recorded by the M2 measuring microphone, the difference is almost 10 to $15 \mathrm{~dB}$ in the whole spectrum. Thus by measuring we have found a considerable influence of the technical condition of the track on the noise in the interior of the passenger railway wagon. The impact of the technical condition of the track on the noise in the interior of the passenger car is much higher than the effect of the running speed on the increase of the noise of aerodynamic origin.

\section{Conclusions}

As the most important outputs from the research activities in the above mentioned issues it can be summarized:

- Creating new models showing the sound reduction and absorptive properties of porous materials and determining the energy balance of the acoustic energy transfer through the porous microstructure of the material.

- Application of porous acoustics in the simulation of acoustic energy transmission through the structure of the floor of a railway passenger wagon.

- Performing acoustic analysis at the positions of individual sections representing the different shape and dimensional composition of the sandwich panel structure using simulation in the "COMSOL Multiphysics 5.0" environment.

- Original results of simulation in the form of frequency spectra of sound transition in the original and newly proposed material structure of the floor and walls of the railway passenger wagon.

- Qualitative evaluation and comparison of the results of simulation models in relation to the current state and the proposed application of new STERED ${ }^{\circledR} 200$ material in the car body structure and the use of STERED ${ }^{\circledR} 250$ as an alternative to a wooden grate.

The paper was supported by the Scientific Grant Agency of the Ministry of Education of the Slovak Republic and the Slovak Academy of Sciences in project no. VEGA 1/0766/15 "Research sources of noise emissions from rail transport". 


\section{References}

1. P. Zvolenský, L. Kašiar, P. Volna, D. Barta, Simulated computation of the acoustic energy transfer through the structure of porous media in application of passenger carriage body. Procedia Engineering 187, 100-109 (2017)

2. L. Bavlna, Research of Internal Noise in Vehicles on Depending Floor Structure of Rail Passenger Carriage. [Dissertation thesis], Zilina: SjF ZU, 124 p., (2016)

3. J. Galliková, R. Poprocký, Computer-aided analysis and the consequences of failures of the selected vehicle subsystem. TRANSCOM 2015, University of Žilina, ISBN 97880-554-1048-7, 58-63 (2015)

A. Pultznerová, L. Ižvolt, Structural modifications, elements and equipment for railway noise reduction. In: Procedia Engineering: Theoretical foundation of civil engineering. 91, 274-279 (2014)

4. D. Johnson, J. Koplik, R. Dashen, Theory of dynamic permeability and tortuosity in fluid-saturated porous media. Journal of Fluid Mechanics 176, 379-402 (1987)

5. L. Jaouen, [Online], http://apmr.matelys.com/, Available on: APMR Acoustical Porous Material Recipes: http://apmr.matelys.com/Parameters/Characterization/ Acoustics/ThermalCharacteristicLength.html (2013)

6. T. Bourbié, O. Coussy, B. Zinszner, Acoustics of porous media. (Institut francais du pétrole publications, Paris, 1987)

7. R. E. Garcia, Introduction to the Materials science of Rechergeable Batteries. Tortuosity and Porosity - Tortuosity in Porous Electrodes. (Purdue University, Purdue, 2014)

8. Y. Champoux, J. Allard, Dynamic tortuosity and bulk modulus in air-saturated porous media. Journal of Applied Physics 70, 1975-1979 (1991)

9. J. Julina, Akustické vlastnosti vybraných stavebních materiálů. (Univerzita Tomáša Batu v Zlíne, Fakulta technologická, Ústav fyziky a materiálového inžinierstva, Zlín, 2008)

10. J. Oreský, S. Žiaran, Noise and vibration in practice. In: S. Žiaran (Ed.), Prenos vibroakustického vlnenia diskontinuitou, 63-66, (Nakladatel'stvo STU Bratislava, 2011)

11. M. Matyka, J. Gołembiewski, Z. Koza, The velocity distribution in a random porous medium. Proceedings of the 5th International Con-ference on Porous Media and its Applications in Science and Engineering, p. 1, Kona, Hawaii: Engineering Conferences International, (2014)

12. EN ISO 3381, Brussels: CEN - European committee for standardization, (2011) 